\title{
The Form and Style of Gnomic Hypermetrics
}

\section{Megan E. Hartman*}

\begin{abstract}
Gnomic poems have often been noted for their unusual metrical style. One aspect of their style that stands out is the hypermetric usage, both because these poems contain a notably high incidence of hypermetric verses and because the verses are frequently categorized as irregular. This paper analyses hypermetric composition in Maxims I, Maxims II, and Solomon and Saturn in detail to illustrate the major stylistic features of gnomic composition. It demonstrates that, contrary to the conclusions of some previous scholars, the hypermetric verses basically follow the form for hypermetric composition that can be found in most conservative poems, but with the inherent flexibility of hypermetric metre pushed to a greater extent than in most narrative poems, making for lines that are longer, heavier, and more complex. This alternate style highlights the importance of each individual aphorism and characterizes the solemnity of the poems as a whole. By composing their poems in accordance with the trends of this specialized style, poets may have been marking their composition as separate from narrative poems and encouraging their audience to consider each individual poem in the larger context of Old English wisdom poetry.
\end{abstract}

Key words: hypermetrics, Maxims I, Maxims II, Old English meter, oral formulaic theory, Solomon and Saturn, wisdom poetry

\section{Introduction}

In many respects, gnomic poems as a group stand apart from the majority of Old English compositions. In particular, Maxims I, Maxims II, and Solomon and Saturn appear remarkable not only because they present lists of seemingly unrelated and sometimes mundane pieces of wisdom, a quality that has raised many questions among modern critics, but also because the metrical patterning is distinctive. A. J. Bliss (1962: 97) notes the oddities of gnomic composition particularly in his discussion of hypermetric verse, concluding that "[i]t seems clear that the gnomic poetry of the Anglo-Saxons belongs in some respects to a different tradition from the remainder of the poetry." Other scholars such as John C. Pope (1966: 127) and Thomas A. Bredehoft (2003: 153-56) likewise note that the metrical features of gnomic hypermetrics set

* Author's address: Megan E. Hartman, University of Nebraska at Kearney, Thomas Hall 202, Kearney, NE 68849. E-mail address: hartmanme@unk.edu. 
these poems apart from most of the rest of the corpus. Their observations suggest a line of inquiry that has not been subject to detailed analysis in Old English metrical studies: stylistic differences along genre lines. In other poetic traditions, scholars and poets readily acknowledge metrical variation between genres. By the early modern period, poets were switching between tetrameter and pentameter in order to mark the lines as more or less formal, and some even tried their hands at fourteeners when attempting to evoke the truly formalized style of epic poetry. ${ }^{1}$ The cognate Old Norse tradition likewise shows specific variants on fornirðislag, and Snorri Sturlason discussed the purpose of each in the Prose Edda.

In contrast, Old English poetry has, for the most part, been analysed as a monolithic tradition. Studies tend to either take Beowulf as a representative example (see for example Bliss 1962; Pope 1966; Russom 1987; and Suzuki 1996) or pick out a wide-reaching corpus that stands in for the tradition as a whole (see for example Hutcheson 1995; and Momma 1997). Recently, scholars have begun to consider how language change might have affected poetic composition, and some studies separate late poetry from more standard verse in order to discuss changes to the tradition (see in particular Cable 1991; Bredehoft 2004 and 2005; and Hartman 2014). Not much work has been done, however, to isolate stylistic differences that might have been a result of the content or genre of a poem. ${ }^{2}$

Old English scholars avoid this type of study with good reason. Modern ideas of genre cannot and should not be superimposed on Old English poetry; as scholars such as T. A. Shippey (1994) have observed, trying to do so is folly because modern generic conceptions do not accurately characterize Old English poems. However, gnomic poetry - which must have consisted of a valued group of poems since so many poets took up the topic - does have some clearly distinct features. Foremost of those is the lack of narrative structure in most cases; these poems are composed primarily as lists. Because of this clear distinction, some gnomic poems can be singled out and grouped together, even if there are many poems that stand in a grey area between the two types of compositions.

In terms of style, hypermetric verse supplies the most distinctive metrical patterns in gnomic poetry. These are the verses that Bliss and others have

1 See, for example, George Chapman's adaptation of Homer's poetry into English verse.

2 One exception is the small body of work on the style of the metrical charms. Jonathan Roper (2000) notes the differences in alliteration as well as the extensive use of enjambment in the charms. E.G. Stanley (1984: 193-199) also points out some distinctive features of the charms in his comparative discussion of Germanic alliterative discourse. 
singled out as particularly irregular. Hypermetric composition also seems to be closely associated with gnomic poetry since gnomic poems use them to a greater degree than most narrative poets. The structure of hypermetric verse is particularly flexible and the metrical patterns are therefore especially susceptible to change, both due to a shift of style inherent in a genre and to an individual poet's stylistic preferences within the larger structure of the poetic tradition. This study will therefore focus on hypermetric verse as the verses that highlight the stylistic characteristics of gnomic poetry overall.

To illustrate the degree to which gnomic poems do in fact exemplify a separate set of stylistic choices, I examine the hypermetric verses in two groups of poems. The first group consists of the three poems that Bliss singles out as irregular: Maxims I, Maxims II, and Solomon and Saturn. These are by no means all of the wisdom poems in the Old English corpus, but they stand out in some ways from the rest of the wisdom poems for, more than any of the others, they provide eclectic lists of aphoristic sayings. Other wisdom poems have a clearer narrative, or at least focus on a single theme. Because these three poems are so wide-reaching in their wisdom and they basically lack any unifying story, they are most likely to show the features of an alternate metrical style. The second group is a corpus of particularly conservative poems: Beowulf, Genesis A, Guthlac A, Daniel, and Exodus. ${ }^{3}$ Because these poems are so conservative in general, the hypermetric sections illustrate what standard hypermetric composition might have been, especially when viewed as a group so as to account for any variations that are apparent in the different poets' styles. A comparison with these poems will therefore show in what ways the gnomic poems vary from the conservative standard.

In part, this analysis demonstrates some places that Bliss's conclusions could be reconsidered, showing that the composition of these lines is not as unusual as he supposed. It will also reveal places where scribal corruption is a possibility, indicating that the supposed irregularities in these instances might not be a feature of gnomic poetry at all. Once the more wide-ranging differences are explained, a close comparison indicates that the gnomic poems basically follow the traditional standard of hypermetric composition, but they tend to have longer and heavier hypermetric lines than conservative poems, to the point that some of the metrical patterns realized in the gnomic poems never occur in conservative verse. The difference suggests a difference in style that

3 The choice of these poems is based on the analysis of Fulk (1992), which shows that these poems demonstrate certain conservative linguistic and metrical patterns to a higher degree than other poems. Examples of the features he analyses are vowel contraction, analogical restoration of syncopated vowels, and adherence to the metrical principle known as Kaluza's law. 
characterizes gnomic poetry in particular. While the individual poets of the three gnomic poems may have made some unique choices about how to realize this style, the poems all follow the basic trend of composing heavier lines.

The difference does not mean that gnomic poetry is composed in an entirely new metre in Old English. Instead, poets working in the gnomic tradition make use of the flexibility already inherent in hypermetric composition and expand on that flexibility to produce distinguishable, but related, metrical patterns. ${ }^{4}$ These patterns seem especially appropriate to gnomic verse because the longer lines can fit clear gnomic statements into single verses as often as possible - giving each verse greater individual significance while also making them all longer and more complex. The cumulative effect of the metrical difference must have been apparent to the audience, for the longer lines with many additional syllables and even some additional stress words must have taken the poets longer to recite and may also have caused them to alter their pacing through the long strings of unstressed words. The hypermetric verses would therefore have presented recognizable, even familiar, verse patterns, but they would also have a slightly different sound or rhythm that could distinguish wisdom poetry from narrative poetry and help the audience to recognize the gnomic significance of the verse.

\section{Old English hypermetric structure}

Old English metre is arranged as a series of lifts (stressed positions) and drops (unstressed position) combined in four-position verses that occurr paired in a long line. Metrists generally analyse verses as belonging to one of five types:

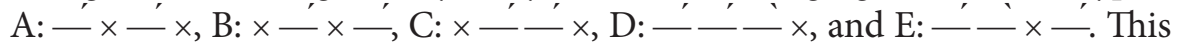
system, which was first devised by Edward Sievers (1893), has been much revised and rethought in the past few decades as metrists have brought more linguistic knowledge to bear on the material. However, although many disagree with some of the principles of his categorization, the basic verse types still

4 In this way, the Old English hypermetric verse of gnomic poetry is distinct from that in Old Norse. In Old Norse poetry, gnomic poems - particularly Hávamál - are frequently composed in ljóðaháttr, a metre that is derived from the more standard eddic fornirðislag. Ljóðaháttr is a distinctive metre because the principles of its composition are quite different from fornirðislag: where the more standard metre quite rigidly avoids extra syllables in a drop, the third and sixth verse in each ljóðaháttr stanza is distinguished from the others with the use of a particularly long drop. Rather than relying on a new set of principles, gnomic hypermetrics in Old English use an exaggerated version of the principles that already exist. 
appear in most of the revised systems of scansion. For this reason, I will use the notation system devised by Sievers, but I will also inform my analysis of the verse structure with the theories of later scholars such as Russom (1987), Suzuki (1996), and Momma (1997).

A hypermetric verse in this system is a verse that is half again as long as a normal verse, making for six positions. Specifically, it consists of a single verse proceeded by a two-position onset. ${ }^{5}$ That onset can either be a heavy onset, which consists of a lift plus a drop $\left(-^{\prime} \times\right)$, or a light onset, which consists of an extended drop $(x \times)$. The onsets in particular are what allow for hypermetric flexibility. They tend to be relatively short, with monosyllabic drops in the heavy onset, as in feorh of fēonda dome (HA1: ' $\times{ }^{\prime} \times{ }^{\prime} \times-\times$ ) 'life from the judgment of the enemy' (Exodus 571a), and trisyllabic drops in the light onset, as in pā hie oðloeded haefdon (hA1: $\times \times \times-\times-\times$ ) 'when they had withdrawn' (Exodus 570b). ${ }^{6}$ However, poets vary the typical length of the drop more than any other position, allowing them to occasionally become quite long: nafre ge mec of pissum wordum onwendad (hA1: $\times \times \times \times \times \times \times{ }^{\prime} \times \times \times-\times$ ) 'you will never change me from these words' (Guthlac A, 376a).

Furthermore, the onsets can be heavier than a normal drop because of the types of words used. According to Hans Kuhn (1969), words can be split into three categories: stress words (Satzteile), particles (Satzpartikeln) and clitics (Satzteilpartikeln). Particles are words such as finite verbs, pronouns, and nonlexical adverbs; they have more prosodic stress than a clitic (which is almost never stressed in Old English poetry), but not as much as a stress word (which should always receive at least a half stress and usually receives full stress), and they receive metrical stress on a variable basis. Because they are prosodically more heavily stressed than clitics, poets tend to limit how often they occur in unstressed positions, especially verse-medial positions. In hypermetric verse, numerous unstressed particles generally appear in the light onset, and even the drop in the heavy onset, a verse-medial position, can contain a particle. The flexibility in both length and weight of the onset is perhaps the most important feature of hypermetric verse; it is that feature that allows poets to add a variety

\footnotetext{
5 For this article, I am using the method of scansion first proposed by Sievers in his article "Der angelsachsische schwellvers" (1887). Sievers proposed a second method of scansion in his book Altgermanische Metric, but Hartman 2010 shows that his first method more accurately describes hypermetric composition.

6 With the exception of Beowulf, all references to Old English poems refer to The Anglo-Saxon Poetic Records (ASPR). The ASPR does not include marks of vowel length in the text, but because they are useful for metrical studies, I have added them here. References to Beowulf come from Fulk, Bjork, and Niles 2008. Translations are mine.
} 
of language material to the drops and to use these hypermetric verses in different ways while still composing according to established poetic conventions.

In addition to creating heavy metrical patterns, the onsets also allow the verses to have more syntactic flexibility. When an onset is filled with particles, it becomes a place in which auxiliary verbs or even finite lexical verbs can be placed without needing to alliterate. Other particles such as pronouns and adverbs can be added there to further clarify the meaning or provide information that might otherwise disrupt the metre. In this way, poets can use hypermetric verse to keep the narrative moving forward steadily, without having to employ variation, and make syntactically straightforward statements.

In contrast to the onset, the cadence tends to be relatively uniform. Unlike verses in normal metre, which do not typically repeat verse types in each subsequent line, the hypermetric cadence consists overwhelmingly of type A verses. Types $B$ and $C$ are especially avoided in the cadence, and types $D$ and $\mathrm{E}$ are used only rarely (they make up $13.5 \%$ of the verse in my corpus of conservative poems). Geoffrey Russom (1987: 59-63) argues that the reason for this simplicity is ease of understanding. Hypermetric verses must have had a special rhetorical purpose in the poem, so the poet would have wanted his audience to notice the shift in metre. Therefore, according to Russom, poets kept hypermetric verses as simple as possible because they were already quite complex, so a simple hypermetric pattern, which would be less likely to be misinterpreted, would allow the audience to follow the shift in rhythm. To further simplify the pattern, poets also composed hypermetric verses mainly in longer sections and kept the heavy onsets in the on-verse (the first verse of the long line), making for an overwhelming number of type HA verses $\left({ }^{\prime} \times \dot{\prime}^{\prime} \times \dot{\prime}^{\prime} \times\right)$ in that position, and a light onset in the off-verse (the second verse in the long line), making for an overwhelming number type $h A$ verses $\left(x \times{ }^{\prime} \times{ }^{\prime}-x\right)$. The cadence of the verse also tends to be quite concise, often consisting of exactly four syllables. While not following these tendencies to the letter, conservative poets tend to compose most of their verses with these simple, short cadences and relatively contained onsets.

Inherent in the principles of Russom's analysis is the idea that the audience must have understood the metre and been able to follow it as a poet recited his poem. Certainly the audience would not have conceived of the metre in the same terms that modern scholars do, but they still could have recognized metrical patterns, as well as any shifts away from the norm. The mere existence of hypermetric lines supports this conclusion because there would be no reason to shift metres in the middle of a poem if the audience would not have registered the change and appreciated how the different rhythms affected the tone of the poem. Any shift away from the more conservative mode of composition 
must therefore have been similarly noticed by the audience, for any expansion of the line would result in a different sort of rhythm upon performance.

Thus, gnomic hypermetric verse would have stood out from more conservative narrative poetry since the gnomic poems as a group do not maintain conservative tendencies as closely. In addition to simply being longer and containing more particles, the verses have the added complexity observed by Bliss. Bliss makes three major observations about the overall irregularity of gnomic hypermetrics: first, that all three poems use a large number of heavy hypermetric onsets in the off-verse; second, that the two Maxims poems both use a large number of what he terms "double hypermetric verses," which contain four fully stressed positions; and finally, that Maxims I in particular contains a large number of remainders (96-97). In all of these cases, the verses fail to maintain the simple patterns that are so important to hypermetric composition elsewhere and instead bring in extra complications that could potentially make the metre more difficult for the audience to recognize. Yet multiple poems are composed this way, suggesting that these unusual trends were not the result of a single poet's whim or incompetence but instead a different style of hypermetric composition.

\section{The structure of the onsets}

One hypermetric feature of the three gnomic poems that distinguishes them from conservative poems is the structure of the onsets. In conservative hypermetric composition, the drop in the onsets, especially the heavy onset, tends to be relatively short. In gnomic poetry, these drops are frequently expanded, making the lines seem unwieldy and irregular. However, while the composition may look different from more conservative composition, gnomic poets do in fact follow the same general principles for the composition of the onsets; they simply take further advantage of the inherent flexibility of hypermetric composition.

\subsection{The light onset}

The light onset falls closer to the parameters set by the conservative poems than the heavy onset, mostly because the light onset is the least restrictive of all positions, so it is variable even in the conservative poems. In terms of the length of the onset, the two groups are roughly comparable, though even here the gnomic poems show a tendency toward longer verses. 
Table 1. The number of syllables in the light onset of conservative versus gnomic poems (\%)

\begin{tabular}{|l|c|c|c|c|c|c|c|c|}
\hline & $\mathbf{1}$ & $\mathbf{2}$ & $\mathbf{3}$ & $\mathbf{4}$ & $\mathbf{5}$ & $\mathbf{6}$ & $\mathbf{7}$ & $\mathbf{8}$ \\
\hline Maxims I & 0 & 13.8 & 31.0 & 29.1 & 19.0 & 8.6 & 3.2 & 0 \\
\hline Maxims II & 0 & 0 & 33.3 & 0 & 66.7 & 0 & 0 & 0 \\
\hline Solomon and Saturn & 0 & 3.3 & 33.3 & 23.3 & 23.3 & 13.3 & 0 & 3.3 \\
\hline Gnomic poems total & 0 & 9.9 & 31.9 & 23.1 & 22.0 & 9.9 & 2.2 & 1.1 \\
\hline Conservative poems & 0 & 16.1 & 32.2 & 35.6 & 14.1 & 1.3 & .7 & 0 \\
\hline
\end{tabular}

While the numbers are generally similar, the gnomic poems have one onset that is longer than any in the conservative poems and they have more onsets with five to seven syllables. Apart from that difference, the basic tendencies are the same. Neither of the groups permits a monosyllabic light onset and both tend towards onsets in the middle range. The only difference in that regard is that the gnomic poems include a five-syllable onset in this middle range, where only three- and four-syllable onsets are most heavily favoured in the conservative poems. Significantly, this trend holds true to at least some degree in all three gnomic poems. Maxims II does not have as many of the very long verses, but the majority of the verses have five syllables in the light onset, though with only three total verses with a light onset, it does not provide as reliable statistical data. The other longer examples are split between Maxims I and Solomon and Saturn.

The words used to fill the light onset are likewise roughly the same in the two groups of poems. Similarly to the conservative poems, the gnomic poems mark the weight of the extended drop in a light onset with one or more particles. Two onsets lack a particle, ${ }^{7}$ but such weak drops appear even more rarely than in the conservative poems, where eight such onsets occur. The light onsets are also similar in the two groups of poems because they have more than one particle the majority of the time, with only 6 onsets in the gnomic poems $(6.6 \%$ of the light onsets) that contain just one and 10 in the conservative poems (7.8\% of the light onsets). Thus the light onset in gnomic poems has a slight tendency to be longer and heavier than the onsets of the conservative poems, but they basically show the same compositional style.

\footnotetext{
7 The verses in question are ond pine heortan gepohtas 'and the thoughts of your heart' (Max-
} ims I 3b) and under foldan scēatas 'under the surface of the earth' (Solomon and Saturn 459b). 


\subsection{The heavy onset}

The heavy onsets in the gnomic poems differ more substantially from those in the conservative poems because gnomic poets fill the drop with more syllables and use particles more frequently. Again, the gnomic poems tend to have longer onsets than the conservative poems, though in this case more so.

Table 2. The number of syllables in the heavy onset's drop in conservative versus gnomic poems (\%)

\begin{tabular}{|l|c|c|c|c|c|c|c|}
\hline & $\mathbf{0}$ & $\mathbf{1}$ & $\mathbf{2}$ & $\mathbf{3}$ & $\mathbf{4}$ & $\mathbf{5}$ & $\mathbf{6}$ \\
\hline Maxims I & 0 & 34.7 & 29.3 & 17.3 & 12.0 & 4.0 & 2.7 \\
\hline Maxims II & 0 & 53.8 & 23.1 & 23.1 & 0 & 0 & 0 \\
\hline Solomon and Saturn & 0 & 45.0 & 25.0 & 15.0 & 15.0 & 0 & 0 \\
\hline Gnomic poems total & 0 & 38.9 & 27.8 & 17.6 & 11.1 & 2.8 & 1.8 \\
\hline Conservative poems & 5.3 & 51.6 & 30.6 & 11.6 & 1.0 & 0 & 0 \\
\hline
\end{tabular}

The gnomic poems have several instances of onsets that are longer than any found in the conservative poems. In addition, the unusually short verses that have no drop in the onset ${ }^{8}$ do not occur at all in the gnomic poems. The proportion of verses that contain longer drops differs as well. Although the gnomic poems contain monosyllabic drops in the heavy onset more frequently than polysyllabic ones, the tendency is not as overwhelming as in the conservative poems, and more verses have the longer patterns that the conservative poets avoid. Maxims II is an exception to the rule; it contains a maximum of three syllables in the drop, which is also the longest drop that appears frequently in the conservative poems. However, trisyllabic drops are equally as common as disyllabic ones in Maxims II, showing a slight tendency towards longer onsets even in this poem.

In addition to longer drops in the onset, these poems also have heavier drops: 64 verses (59.2\% of the verses with heavy onsets) have at least one particle in that position, 27 of which $(25.0 \%)$ have more than one. In the conservative poems, 13 verses $(13.7 \%)$ have a particle in the drop of the heavy onset, and of those only 5 (5.3\%) have multiple ones. On the other end of the spectrum, 19 verses (16.4\%) contain only the unstressed final syllable of a word in the gnomic poems, as opposed to $32(38.7 \%)$ in the conservative poems. The Maxims I poet takes particular advantage of these longer, heavier drops

8 Several of these verses have anacrusis, which causes Sievers (1887: 468-69) to suggest that some of the patterns might be inverted. The one example that does not, men mid siðian (Genesis A 2869a), is considered corrupt by Pope (1966: 103). 
and includes 17 verses ( $22.7 \%$ of the verses with heavy onsets in that poem) with a clause break in that position (something that happens only twice in all of the conservative poems combined). Most of these verses are quite complex and have at least one particle in the drop. These numbers show that, on average, the drops in both types of hypermetric onsets, but especially the heavier onset, tend to be longer and more complex, making for weightier lines overall.

Thus, one major factor that causes hypermetric verses in gnomic poems to look so unusual when compared to the most conservative Old English verses is the freedom with which the poets use the onsets. While the minimal length is still common, the drop of each onset is often longer and, in the case of the heavy onset, heavier than in the conservative poems. These verse patterns should not be considered irregular, however, because hypermetric onsets are constructed to allow for a large amount of variability; the gnomic tradition consist of verses that demonstrate that variability to a greater degree than narrative poems do, specifically, containing the longer options with greater frequency. This style creates a different rhythmic pattern that would have been heavier and taken longer to say simply because the verses are longer and contain more words with a degree of prosodic stress. In poems that often list gnomic statements that are one or two verses long, this style would draw out each individual statement, giving it particular emphasis.

\section{The structure of the cadence and the verse}

While the long onsets certainly make gnomic hypermetric composition appear unusual in some ways, it is the form of the cadence, together with the overall pattern of the hypermetric verses that results from the unusual cadences, where the majority of the irregularities that Bliss and others cite can be found. This is not to say that the cadences are irregular as a whole - the vast majority of the verses in gnomic poems contain a cadence of type A1, just as the conservative poems do - but merely that more possible irregularities exist. Again, though, many of these verses, while not conforming to the norm, still fall into permissible patterns of hypermetric composition, especially when some of the scansions that Bliss proposes are reconsidered. Some irregularities do remain, but the majority of the verses show the general tendency in gnomic composition to take full advantage of the flexibility of the hypermetric form in order to extend the lines, rather than a disregard for the conservative metrical constructions. Greater flexibility of the cadence might therefore represent another gnomic feature that poets used and ultimately capitalized on in this type of poem. 


\subsection{Remainders}

Bliss focuses on two groups of problematic verses. The first of these are the verses he terms remainders, which means verses he cannot fit into a permissible metrical pattern. He identifies six hypermetric remainders in the Old English corpus, all of which occur in the gnomic poems (1962: 96):

Dol bip sē pe his dryhten nāt (Maxims I 35a)

'Foolish is he who does not know his God'

Sēoc sē bip pe tō seldan ieteð (Maxims I 111a)

'Sick is he who eats too seldom'

ofercumen bip hē, æær he ācwele (Maxims I 113a)

'he is overcome, before he dies'

Mūpa gehwylc mete pearf (Maxims I 124a)

'Each of mouths needs food'

pæt ēce nīð ǣldum scōd (Maxims I 198a)

'that eternal hatred injured men'

wunnon hïe wið dryhtnes miehtum (Solomon and Saturn 329a)

'they struggled against the might of the lord'

While it does seem striking that this group of poems, particularly Maxims $I$, should contain this many hypermetric remainders when none of the other poems have any, not all of these verses should necessarily be scanned as Bliss suggests. Firstly, Maxims I 35a and 111a can both be analysed as a type HB1. Bliss's inability to scan them results from his complex method of scansion rather than any metrical problems in the verse. ${ }^{9}$ There is nothing particularly unusual about these verses when compared to other hypermetric verses and, if they are scanned according to Sievers's first system of hypermetric analysis rather than Bliss's system of replacement, they are perfectly regular.

Secondly, Maxims I 198a could be scanned as a regular type aHD4 $(\times-$

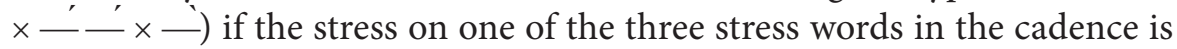

9 According to Bliss's system of replacement, the onset must be analysed as part of a verse. Furthermore, if the cadence is a type that opens with an unstressed position, the first verse in the sequence should be a type that ends in a stressed position, a type B or E, possibly with the first drop removed if it is a type B. However, because the drops in these verses are formed by multiple function words, the underlying verses cannot be a type $\mathrm{E}$ (which requires secondary stress in the drop) or a type B (which cannot have a second drop longer than two syllables). 
subordinated. This scansion presents two problems. First, although normal verses can have three stress words, hypermetric cadences rarely do because they so frequently employ the simplest patterns possible. Only one appears in the conservative poems, Engel in pone ofn innan becwōm (HD4: ${ }^{\prime} \times \times \times \times$ $\left.{ }^{\prime} \times \times-{ }_{-}^{\prime}\right)$ 'The angel came inside, in the oven' (Daniel 237a), and they occur nowhere else in gnomic poetry. However, the verse from Daniel is not exactly an anomaly because the cadence ends with a collocation that frequently closes type B or D4 verses. Since it was formed using traditional language and an established verse pattern, the verse reinforces the argument that any valid verse type can appear in the cadence (even if some appear more rarely), which in turn shows that a D4 pattern with three stress words need not be ruled out as too complex. The second deviation is more irregular: the alliteration falls on the first and third stress in the verse rather than the standard first and second. Nevertheless, the verse does present a valid metrical pattern, so it should probably be considered a standard hypermetric verse type with delayed alliteration instead of an outright remainder.

Solomon and Saturn 329a contains another non-standard alliteration pattern. Not only does this on-verse lack double alliteration, it also alliterates on the $w$ of wunnon, which is irregular because it does not conform to the alliterative tendency known as the rule of precedence: verbs are allowed to participate in the alliteration when they precede a noun only if the following noun alliterates as well. In this case, two nouns follow the verb, and neither one alliterates. Similarly to Maxims I 198a, however, and especially because strange alliterative patterns, including breaking the rule of precedence, are common in Solomon and Saturn, the verse should likewise be categorized as a standard verse pattern, in this case a type HA1 $\left(\stackrel{\prime}{\prime}^{\prime} \times \times \times \stackrel{\prime}{\prime}^{\prime} \times \stackrel{\prime}{-} \times\right)$, with faulty alliteration.

That leaves just two verses that do not fit into any verse pattern: Maxims I 124a (Müpa gehwylc mete pearf) and Maxims I 113a (ofercumen bip hē, yōer he $\bar{a}(w e l e)$. Thus, Bliss is correct that the gnomic poems contain all the hypermetric remainders, but with just two remainders, these poems - or more specifically, Maxims I, since both remainders appear in that single poem - do not seem exceptionally irregular. In fact, they may not be irregular at all in this regard, since the possibility should be considered that these two verses are the product of scribal error. Because hypermetric verses use freer verse patterns, a scribe might more easily make a mistake when transcribing one of these lines and not catch the metrical irregularity. The longer onsets used by the Maxims I poet, which create verses that are loosely structured and therefore hard to recognize, would increase this possibility. With so few remainders to provide evidence for this type of irregularity, it is reasonable to assert that they are 
both a result of scribal error and that the gnomic tradition does not stretch to include verses that did not conform to the basic principles of the alliterative long-line. Even if these two verses are authorial - and with both sense and syntax intact in these passages, it is possible that they are - two verses in a 204-line poem do not constitute an exceptional irregularity. If the Maxims I poem took greater liberties with the metre and included a few verses that cannot readily be scanned, he avoided them for the most part.

\subsection{Four-stress verses}

A second group of unusual verses is made up of verses that have four stressed positions instead of three, which Bliss calls "double replacement" verses (1962: 95-6). Bliss identifies a total of thirteen such verses in the Old English corpus, though feasible alternatives have been presented for the three verses that occur outside of the gnomic poems. ${ }^{10}$ The verses from the gnomic poems that Bliss argues have four stresses are: ${ }^{11}$

Glēawe men sceolon gieddum wrixlan (Maxims I 4a)

'Wise men should exchange maxims'

Snotre men sāwlum beorgað (Maxims I 36a)

'Wise men guard their souls'

trymman ond tyhtan pæt he teala cunne (Maxims I 46a)

'strengthen and lead so that he knows rightly'

cēne men gecynde rīce (Maxims I 58a)

'the bold one [holds] his natural kingdom'

wïdgongel wīf word gespringeð (Maxims I 64a)

'the wandering wife spreads words'

Sceomiande man sceal in sceade hweorfan (Maxims I 66a)

'The man causing shame shall turn in the shadow'

Wif sceal wip wer wære gehealdan (Maxims I 100a)

'A woman shall hold faith with her husband'

10 The verses in question are Beowulf 1166a, Daniel 237a, and The Wanderer 65a

11 Bliss also includes Maxims I 185a (wērig scealc wip winde rōweb 'the weary crewman rows against the wind') in his list; however, this example does not provide evidence for an unusual metrical pattern because it is the result of an emendation. 
Fela sceōp meotud pæs pe fyrn gewearð (Maxims I 164a)

'The creator created many things, of those things which occurred formerly' pēof sceal gangan pȳstrum wederum (Maxims II 42a)

'the thief shall go in dark weather'

Once again, some of these verses could be analysed differently. Maxims I $4 \mathrm{a}, 36 \mathrm{a}, 58 \mathrm{a}$, and $66 \mathrm{a}$ could be reanalysed because they all have the second stress on the word men or man. Normally man should receive stress because it is a noun. But the similar mon can be used as an indefinite pronoun, and then it is treated as a particle and regularly unstressed. Technically the two words are distinct and should be treated differently, but ultimately they fall together and by the Middle English period both are regularly unstressed. In Old Norse as well, maðr can be unstressed. ${ }^{12}$ In all four cases here, men or man refers to a general subject, even though the more specific noun occurs, so the word is being used similarly to mon. Furthermore, in each case, if unstressed, it would fall in the heavy onset, which is a natural place for one or more unstressed words. ${ }^{13}$

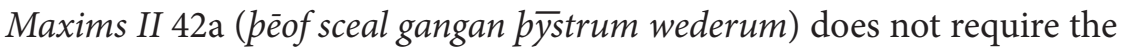
fourth stress in the line because one of the four stresses would fall on an infinitive, gangan. As a stress word, infinitives ought to receive stress invariably, but they do not in fact do so. ${ }^{14}$ Kuhn (1933: 5) argues that they should sometimes be considered particles and are therefore subject to variable stress. Again, the questionably stressed word in this poem comes in a position that can easily receive an extra, possibly heavier, unstressed word, namely the drop of a heavy onset that begins a clause. Therefore, it seems likely that gangan should be

12 Some examples of unstressed maðr include Fafnismál 7.3, and Hávamál 6.2, 6.8, 8.5, 9.5, 10.2, and 11.2. It is telling that many of these examples of unstressed maðr can be found in the gnomic poem Hávamál, where the word is unstressed as often as not. It is possible that the word functions differently in gnomic poetry, since it occurs so frequently and is used similarly to the generic particle sum.

13 In one instance, Maxims I 58a (cēne men gecynde rīce), leaving men unstressed would create a violation of Kuhn's first law: the verse does not open a clause, so if men should be considered a particle here, it would be an unstressed particle outside the first drop of the verse clause. However, in two other verses, Maxims I 4a (Glēawe men sceolon gieddum wrixlan) and Maxims I 66a (Sceomiande man sceal in sceade hweorfan), putting stress on the word would cause a violation of Kuhn's first law because it would separate a particle from the first drop.

14 Some examples of verses with unstressed infinitives are The Battle of Maldon 39, The Wife's Lament 42, Genesis A 2483, 2820, the Phoenix 165, and Christ and Satan 590 (see Pope and Fulk 200: 96). 
unstressed. Thus, these five verses all appear perfectly regular if scanned with only three stressed positions: the heavier unstressed particles are grouped together in the onset and the cadence forms a regular verse type. What is notable about them is that they create metrical patterns that are on average longer and heavier than those of the typical conservative poems, a trend that characterizes gnomic poetry overall.

That leaves four verses that clearly have four stresses in the line: Maxims I 46a, 64a, 100a, and 164a. None of these verses have either a cadence in which one of the stresses could be subordinated to create a three-stress line or a word of variable stress near the beginning of the verse that could be part of the drop. ${ }^{15}$ Even though these verses appear unusual with their extra stressed position, they are not completely irregular. Douglas Simms (2003: 67-87) observes that these verses all have a normal verse type in the cadence, just as a regular hypermetric verse would. ${ }^{16}$ While not all the verses use the type A1 pattern that is most typically found in the hypermetric cadence - Maxims I 46a (trymman ond tyhtan poet he teala cunne) has a type $\mathrm{C} 2\left(\times \times \dot{v}^{-} \times\right)$in the cadence and Maxims I 164a (Fela sceōp meotud poes pe fyrn gewearð) has a type B1 ( $\times x-\times$ -) - all the cadences are perfectly regular verses types.

The structure of the onset is not as clear. While Maxims I 46a and Maxims I 64a have the pattern of a normal verse, a type A1 $\left(\check{L}^{\prime} \times x \dot{\prime}^{\prime} \times\right)$ and a type $\mathrm{E}$ (-'- $\times$ - $)$ respectively, other onsets cannot be scanned as easily. ${ }^{17}$ Maxims I 100a and 164a do not appear as regular, both with just three positions made up of two stresses bookending a single drop. Each verse does have a verb in the

15 One particle does come at the beginning of a verse, fela in Maxims I 164a. Yet while fela can occasionally be unstressed (see for example Beowulf 929a, Daniel 593a or Genesis A 622a), it much more often appears in a stressed position. In addition, fela bears the alliteration here, and the next stress word does not alliterate, so it must receive stress in order to fulfil the alliterative requirements.

16 Simms also adds that the onset seem to have the form of a normal verse as well. However, he includes Maxims I 58a and 66a and Maxims II 42a in his list of four-stress verses in the gnomic poems, which creates a larger proportion of regular onsets. If only Maxims I 46a, 64a, 100a, and 164a are analysed as four-position verses, then exactly half of the verses contain an onset formed from a normal verse, making for less certain evidence.

17 Bliss (1971) notes the regularity in some onsets and revises his original analysis by dividing the long on-verse into a normal line and then calling the following off-verse a "short" line, which is equivalent to the Old Norse full line. However, this proposed change would create an unusually large number of normal lines in the midst of hypermetric passages, as well as full lines which would have continued alliteration, where Old Norse full lines and other orphan verses in this poem instead generally have internal alliteration. It therefore seems preferable to maintain the analysis of a four-stress verse when the verse unambiguously contains four stressed positions. 
onset, so it would be possible to give the verbs secondary stress to form valid

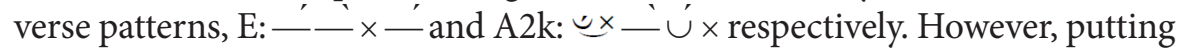
stress on these verbs in the first drop of the verse clause would be unusual, especially since unstressed verbs appear so often in this position in hypermetric verse. Without further examples to compare, it is impossible to say which scansion is better. Either way, the verses consists of a normal cadence with an onset that has been expanded to an especially large degree.

Although these verses could also be a product of scribal error, with twice as many verses as the remainders, the probability is not as high, especially given that these verses have a clearer metrical structure. The four-stress verse might instead be a particular feature of gnomic hypermetric verse. Simms (2003: 67-87) proposes a logical explanation for why these unusual lines may have developed: they create rhetorical emphasis in an already rhetorically heightened passage of poem. In light of the fact that all of the clear examples occur in Maxims I, a poem that is more than one third hypermetric, the idea that the poet would add an extra stress word to the line for further emphasis seems natural. Indeed, most of the lines occur in relatively long hypermetric passage of at least six and as many as nineteen lines - only line 146a stands by itself; it occurs in a particularly irregular passage that has several small hypermetric groupings as well as several verses without a verse pair - so an extra lift would help to make any verse stand out in these locations. The explanation is also in line with the general trend toward longer and more complex verses that can be found in gnomic hypermetrics as a whole.

\subsection{Type $B$ and $C$ verses}

In addition to the two irregularities discussed by Bliss, a third unusual metrical pattern appears frequently in gnomic hypermetrics: types HB and HC. There is nothing strictly irregular about these verses, since the cadence does follow a normal verse pattern, but they are very rare in hypermetric verse. As Max Kaluza (1895: 377) shows, poets generally avoid using verse-types that open with an unstressed position in the cadence to avoid ambiguity; because the onset always ends in a drop, starting the cadence with a drop would put two drops next to each other, making those two positions indistinguishable from a single long drop. The conservative poems use those two verse types in the cadence, but only 
a total of four times in 244 verses. The gnomic poems have fourteen possible examples, which mostly appear to be regular, valid examples of the verse types: ${ }^{18}$

Type B:

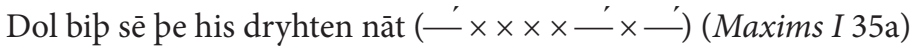

'Foolish is he who does not know his lord'

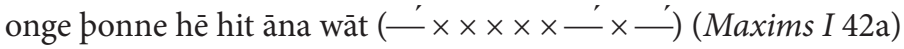

'cruel when he alone knows it'

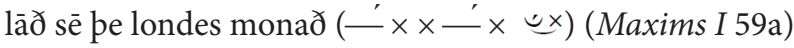

'hateful is he who demands land'

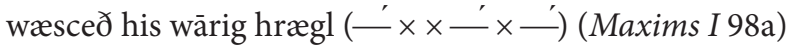

'washes his dirty clothing'

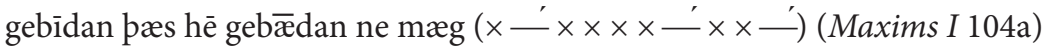

'to wait for that which he cannot impel'

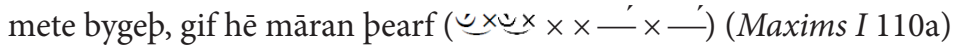

'acquires food, if he needs more'

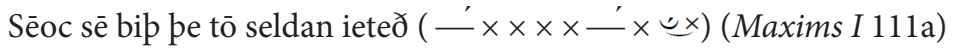

'Sick is he who eats too seldom'

Type C:

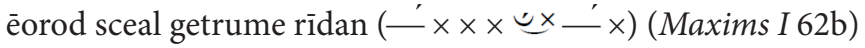

'the troop shall ride in a host'

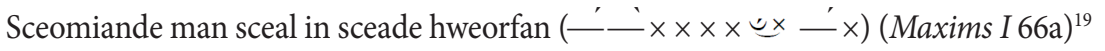

18 Five of these are verses that Bliss analyses as a different verse type. I have already discussed Maxims I 35a and 111a and shown why they need not be analysed as remainders. Similarly, he analyses the cadence of Maxims I 104a as a type E and calls the whole line a type $1 \mathrm{~A}^{\star} 1 \mathrm{c}(2 \mathrm{E} 1 \mathrm{a})$. However, this unusual scansion, which requires placing a half-stress on an inflectional ending, is only required by the constraints of Bliss's system of replacement. With those restrictions removed, the verse can be scanned as a regular type HB2. Also as discussed above, Maxims I 66a need not be scanned as a four-stress pattern if man does not receive stress; Bliss does agree that the cadence is formed of a type- $C$ verse. Finally, Bliss scans the cadence of $114 \mathrm{a}$ as a type A, which must be a mistake because that would require a long vowel on mete. The word clearly means 'food' and has a short vowel.

19 As a ùo-noun, sceade would originally have been spelled sceadwe, making for a long root syllable on the noun and a type-A cadence in this verse (see Campbell \$596). This verse therefore presents an uncertain example because there is no way to tell whether the poem was composed 
'One causing shame shall wander in the shadow' hām cymeð, gif he hāl leofað ( '

'he comes home, if he lives healthy' Mægen mon sceal mid mete fēdan ( $\underbrace{e} \times \times \times \underbrace{e x} \perp^{\prime} \times)$ (Maxims I 114a)

'One shall feed his strength with food' Wel mon sceal wine healdan $({ }^{\prime} \times \times \times \underbrace{e} \times-x)$ (Maxims I 144a)

'One shall hold his friends well' Cain, pone cwealm nerede $\left(\stackrel{\prime}{-} \times \times \perp^{\prime} \in \times\right)$ (Maxims I 197a)

'Cain, whom death preserved'

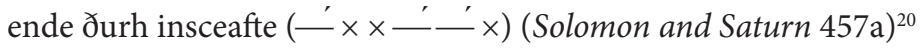
'an end through internal generation'

Emendations have been proposed for two verses, Maxims I 62b and 197a, which means that the metrical pattern might not be authorial in these cases, but both changes are small. In the first case, the ASPR replaces the manuscript worod with cognate erorod to provide the alliteration, and in the second, Shippey (1976: 134) points out that the sense of manuscript reading, which is kept in the $A S P R$, is strained and that replacing nerede with serede would create a more logical translation. ${ }^{21}$ Since the errors are so small, they do not influence the scansion of the verse. While they might show evidence of a larger scribal error, it is also possible that any error consisted of only these few letters, leaving the metre intact.

These two verses are the only ones that show any visible evidence of scribal error, leaving a large number of clear examples that present strong evidence that the metrical pattern was considered a valid alternative to the usual type-A cadences. These verse types affect the overall metrical patterns in a few different ways. First, they allow for more variability, since they increase the number of verses that differ from the type-A1 pattern and even introduce a clashing

late and the spelling is in fact authorial, or it was an earlier poem and the scribe changed the spelling to the later variant.

20 It is possible to analyse this verse as a normal rather than a hypermetric verse by not promoting the stress on the final compound, making the verse a type $\mathrm{D}^{*} 1\left(\dot{\prime}^{\prime} \times \times \dot{\prime}^{\prime}-\dot{\prime} \times\right)$. The verse looks more regular as a type $\mathrm{D}^{\star} 1$ since it is short and ends in a compound, but the hypermetric scansion may be better because the verse occurs in the middle of a hypermetric passage.

${ }_{21}$ As it stands, the verse would need to be interpreted along the lines of 'Cain, whom death preserved.' Shippey's emendation allows him to translate the verse as 'Cain, who plotted the murder.' 
stress pattern. Secondly, and typically of these gnomic poems, they increase the length of the lines because the initial drop tends to be particularly long in order to signal that it forms two adjacent drops. Noticeably, these types are not distributed evenly throughout the three poems but instead, apart from the one short example in Solomon and Saturn, they are found exclusively in Maxims $I$. In fact, in terms of the cadences, almost all of the unusual verses occur in Maxims I. Thus, the poet who employs the highest incidence of hypermetric verses overall also employs the more unusual features that characterize gnomic diction most fully.

A closer look at the unusual metre of the gnomic poems therefore reveals two important points. First, the Maxims I poet tends to use unusual stress patterns more often than the other poets, particularly where the cadence is concerned. And second, none of the poems, including Maxims I, are as irregular as Bliss asserts. There are some unusual verses, but very few of them are actual remainders. Most of them are type $\mathrm{B}$ and $\mathrm{C}$ verses, which more traditional poets tend to avoid but do not eliminate entirely. These verses fit well in the gnomic tradition because the long first drop allows the poets to compose the long, heavy verses, possibly with multiple particles or a clause break in the opening drop, that characterize gnomic style. In addition, these verses frequently employ the diction that likewise marks a statement as gnomic and are even often used in a particular poetic formula that seems to be used exclusively to share wisdom. ${ }^{22}$ Since they also conform to normal versetypes, they still produce verse patterns that fit into the overall Old English poetic tradition. Thus, by using so many type $\mathrm{B}$ and $\mathrm{C}$ verses, the Maxims $I$ poet adheres to the overall verse principles while still maintaining and perhaps highlighting features of gnomic composition, thereby contributing to the sound pattern that marks gnomic poetry. The four-position verses might be another example of the same principle. While such verses do not appear frequently in the Old English corpus, they do seem to be a logical extension of hypermetric verses: the poet adds yet one more stress to increase the weight of the lines further still. Particularly in a poem like Maxims I that uses so many hypermetric verses, it would be reasonable for the poet to expand his uses of hypermetric patterns and play with them more to create variety and to add further emphasis to important moments within gnomic passages. The combination of length, weight, and foregrounding of the specialized diction might therefore characterize the gnomic poems overall; the poets employ a

22 Momma (1989: 423-426) first identified this particular system and noted that it occurs across both gnomic and narrative poems when the poet wished to share a wise saying; she labelled it "the gnomic formula." 
larger percentage of hypermetric verse to show the import of their topic, and the variety of hypermetric verses the Maxims I poet in particular composes demonstrates his comfort with the features of the gnomic tradition and his ability to use it to place emphasis on important gnomic statements while also employing the rhythms that distinguish gnomic poetry from the conservative sound patterns typical to narrative poems.

\section{The structure of the lines}

Another result of the greater flexibility and tendency toward weighty lines in gnomic composition is that hypermetric lines can be structured and distributed in non-standard ways throughout the poems. Normally, a hypermetric line consists of a heavy onset in the on-verse and a light onset in the off-verse, and it appears in a passage of multiple hypermetric lines. The gnomic poems show a large number of alternatives: lines that have a light onset in the onverse or a heavy onset in the off-verse, as well as hypermetric lines or verses that occur outside of a hypermetric passage and normal verses that intrude into hypermetric passages. Just having variant distribution patterns does not make the gnomic poems stand out; alternatives occur frequently in conservative poems. For example, lone hypermetric lines occur among normal lines in Guthlac A, Genesis A, and Daniel, and Daniel in particular includes many normal verses in the middle of the hypermetric passages. Furthermore, those same three poems use the light onset in the on-verse at times, and the Guthlac A poet makes extensive use of that pattern. Since they occur in a number of conservative poems, such features ought not be considered a mark of irregularity per se, but neither are they the norm. It is therefore striking that all three gnomic poems differ from the standard distribution patterns in all the ways listed above. The ready use of alternative patterns suggests that the gnomic tradition allows for a wider range of possibilities than standard hypermetric convention does and includes whatever patterns fit the traditional gnomic language.

\subsection{The distribution of the on-sets}

The first of the irregular distribution patterns, a light onset in the on-verse, is one that occurs frequently in the conservative poems: as a group they employ the alternative $23.0 \%$ of the time, and the Guthlac A poet in particular uses it $41.1 \%$ of the time. The extensive use of the light onset in the on-verse in 
Guthlac A suggests that the pattern was considered a viable alternative, yet the lack of the alternative in Beowulf and Exodus shows that it is still a break from strictly traditional composition. In the gnomic poems, the alternate pattern occurs 7 times in Maxims I (9.8\% of the hypermetric on-verses), 7 times in Solomon and Saturn (28\%), and twice in Maxims II (25\%). Thus, the poems as a group employ the pattern at about the same rate as the conservative poets do overall, but not to nearly the extent that Guthlac A demonstrates they could. This moderated use of the light onset in these poems makes sense when the form of the onset is considered. A light onset in the on-verse is a practical alternative because it provides more space for function words in any given line, allowing poets to compose with straightforward syntax. But it is also a lighter pattern, since it removes one stress from the hypermetric line and includes only small words that can be spoken rapidly. The structure therefore makes the light onset a very valuable tool, and because gnomic composition is so flexible, the gnomic poets employ it where they see fit. Nevertheless, the onset decreases the weight of the lines, since it eliminates a stressed position, so it contradicts the general tendency of gnomic poetry to employ heavy lines and therefore does not become a characteristic feature of gnomic diction.

Where the gnomic poems are distinctly differentiated from the more conservative poems is the use of the heavy onset in the off-verse. This distribution occurs only once in the conservative poems: Mōg woes his ägen pridda (HA1:

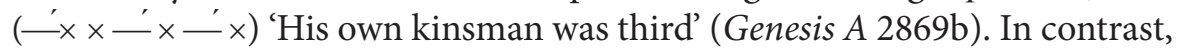
it appears relatively frequently in gnomic poetry, with 29 examples, or $26.8 \%$ of the hypermetric off-verses. All three poets use this pattern, though in this case the Solomon and Saturn poet does not use it as much. The Maxims poets both take full advantage of this alternative. Maxims I contains 18 examples $(21.6 \%$ of the off-verses), which is far more than the 5 occurrences of a light onset in the on-verse. Maxims II has 6 examples (75\% of the off-verses), making that the standard onset for the poem as a whole. The expanded use of the heavy onset creates a more sharply contrasting rhythm because it adds another stress word to the already heavy lines and makes them sound even weightier. This feature, which is only used consistently in these two gnomic poems, might therefore be a specialized and distinctive alternative for the gnomic tradition.

It is also interesting to note the varying degrees to which the poets employ this alternative. Clearly, it fits with the general tendency to make the lines heavier and, given that all three gnomic poems include it, seems to be a viable option for the gnomic tradition overall. Yet equally clearly, the three poets use the pattern in widely different degrees. The contrast suggests that the poets took advantage of a degree of personal choice within the larger confines of the tradition. In this case, the Maxims II poet found the heavy onset particularly 
conducive to his style. More than the other two poems, Maxims II focuses almost exclusively on short, pithy statements, rarely expounding on any of them. The additional heavy onsets give weight to each individual gnome and, in the cases in which each gnome takes up exactly one verse, allow for a symmetry in the lists.

\subsection{Distribution of the lines within the poems}

The distribution of hypermetric verses across the poem is another way in which gnomic poetry appears less constrained than narrative poetry, specifically with hypermetric verses that are paired with normal verses. The exception is by no means the rule: the vast majority of the verses appear paired with a second hypermetric verse in a group of hypermetric lines. The poems also contain four lone hypermetric lines, but this pattern likewise occurs on occasion in many of the conservative poems. Yet even though the poems mostly match the metrically conservative poems in this regard, a notable number of verses are paired with a normal verse, both in longer hypermetric passages and in normal passages. This distribution pattern is not unheard of in Germanic verse overall; in the Old Saxon Heliand, 29 normal verses occur in the middle of a hypermetric passage and 29 hypermetric verses appear outside of a hypermetric passage. ${ }^{23}$ Nevertheless, these distributions are distinct from the conservative composition in Old English, where normal verses within hypermetric passages occur multiple times only in the possibly corrupt Daniel, and even there a completely separate hypermetric verse is avoided.

The first possible distribution pattern, a hypermetric verse paired with a normal verse in the middle of a hypermetric passage, occurs 8 times: ${ }^{24}$

gebīdan pæs hē gebǣdan ne mæg. Hwonne him eft gebyre weorðe (Maxims I 104)

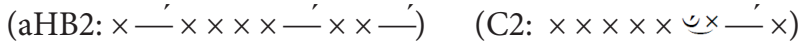

'wait for that which he cannot impel. When it becomes time for him again'

23 These numbers are debatable because Old Saxon hypermetric verses can be very ambiguous. As Suzuki (2004) did, I have excluded all verses with a proper name, since the length of syllables in Biblical names is ambiguous. I have also scanned potentially hypermetric verses outside of hypermetric passages as normal verses where possible, so my list of hypermetric verses is shorter than Suzuki's.

24 Maxims I 196b and 198a and Solomon and Saturn 460a are also paired with normal verses, but these occur at the edge of a hypermetric passage, which appears permissible in the conservative poems. 
ne mæg hē be $\mathrm{p} \bar{y}$ wedre wesan, pēah hit sȳ wearm on sumera (Maxims I 112)

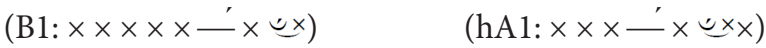

'he cannot exist through the weather, although it be warm in the summer' Wel mon sceal wine healdan on wega gehwylcum (Maxims I 144a)

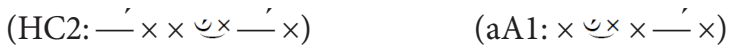

'One shall hold his friends well on each of roads' felafǣcne dēor. $\quad$ Ful oft hine sē gefēra slìteð (Maxims I 147)

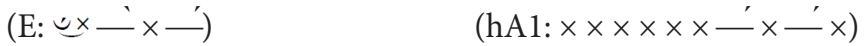
'the very treacherous animal. Very often the companion rends him to pieces' idle hond $\bar{x}$ metlan genēah tæfles monnes,

ponne teoselum weorpeð (Maxims I 183b)

(irregular) (hA1: $\times \times \underbrace{ \pm \times} \times \underline{\prime}^{\prime} \times)$

'Worthless hands suffice for one at leisure, the man given to playing dice, when he throws the dice'

Wearð fǣhpo fy̆ra cynne, $\quad$ sippan furbum swealg (Maxims I 192)

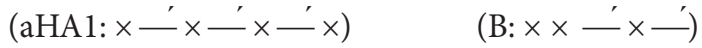

'Hostility came to the kin of men, just as soon as [the earth] swallowed [Able's blood]'

orðanc enta geweorc

pā pe on pysse eorðan syndan (Maxims II 2)

$\left(\mathrm{D}^{*} 4: \stackrel{\prime}{-} \times \stackrel{\prime}{\prime} \times \times\right.$ - $)$

(hA1: $\times \times \times \times \times \stackrel{\prime}{\prime} \times \stackrel{\prime}{-} \times$ )

'the skillful work of giants, those who are on this earth'

āfielde hine ðā

under foldan scēatas, (Solomon and Saturn 459

(irregular)

(hA1: $\times \times \stackrel{\prime}{\prime} \times \stackrel{\prime}{-} \times)$

'then caused him to fall under the surface of the earth'

When looking at this list of hypermetric verses with their normal verse pairs, a few notable patterns emerge. First, two of the hypermetric verses, Maxims I 183b and Solomon and Saturn 459b, are paired with irregular verses, which suggests that some error might exist in the line. Second, five of the verses are paired with verses that can be analysed as a regular normal verse, but are also metrically very similar to hypermetric verses and could potentially have a similar rhythm when performed. Maxims I 104a, 112b, and 192a are all paired with a verse type that opens with an unstressed position, making them similar to verses with a light onset. Although 192a has a relatively short opening drop, the other two are quite long, increasing the similarity. Maxims I 144a is paired with a verse that takes anacrusis in the off-verse, which is quite rare. Because the opening drop is only one syllable long and the light onset, which 
stands in for two positions, is generally longer, the verse seems more logically anacrustic; nevertheless, it does bear a similarity to a type hA $1 .{ }^{25}$ Bliss in fact analyses Maxims II 2a as a hypermetric verse; however, it would be unusual as a hypermetric verse because it only has five positions. ${ }^{26}$ Nevertheless, it resembles a hypermetric verse because it is particularly heavy and has three separate stress words. Third, most of the verses in Maxims I occur in the same hypermetric passage as another unpaired verse or in passages that are quite close to each other.

There are two ways to interpret these trends. Again, the possibility that these are instances of scribal corruption should be considered. Multiple instances of these unpaired hypermetric verses within the same hypermetric passages may indicate that the scribes were confused at these points, and because so many of these verses resemble hypermetric verse, whether they form a normal verse pattern or not, a small change would suffice to create a hypermetric verse. Another possibility is that, given the relative freedom of the gnomic tradition, the poets were not as strict about the groupings. These verses are generally still long and similar in structure to traditional hypermetric verse, so they may not have been perceived as a disruption to the metre at all. The larger number of unpaired hypermetric verses in Maxims I and the existence of such verses across all three poems suggest that they were acceptable in gnomic composition.

The other distribution pattern that is rare in conservative poems but that occurs more often in the gnomic poems is a single hypermetric verse in the middle of a passage of normal verses. In the gnomic poems, Bliss finds seven examples of lone hypermetric verses. In addition to these, seven other verses that occur in normal sections, all in Maxims Ic and Solomon and Saturn, should perhaps be considered hypermetric as well. ${ }^{27}$ At least one of the verses that Bliss identifies shows evidence of corruption, for ofer ðare stylenan helle

25 Bliss does not analyse this verse as hypermetric, although he does so for a second verse that opens with a monosyllable drop (The Order of the World 102a).

26 Bliss calls the verse a type $2 \mathrm{~A} 1(2 \mathrm{E} 1 \mathrm{a})\left(\dot{\mathrm{C}}^{\prime} \times \boldsymbol{\prime}^{\prime} \times \times \times-\right)$, creating a sixth position by putting tertiary stress on the final syllable of enta. Some instances do occur in which the final syllable of a word receives a degree of half-stress even though the word is not a true compound, but in most cases the irregular instance of stress falls on the second element of a quasi-compound (see Fulk 1992: 184-193). Because enta does not contain any separate morpheme, it should probably not receive stress on the second syllable.

27 The lone verses that Bliss identifies are Maxims I 30b, 116b, 149b, 151b, and 164a, Maxims II 47a, and Solomon and Saturn 490a. Additional possibilities are Maxims I 172 and 189, and Solomon and Saturn 236b, 261a, 289a, 337b, and 400b. 


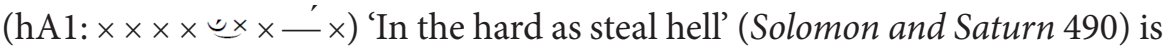
not paired with any verse at all, and although there does not appear to be any break in the manuscript, the sense of the narrative suggests that something has been left out at this point.

If the further potential verses that Bliss does not identify are also hypermetric, the possibility that scribal error could account for all of these verses decreases. The two verses in Maxims I, Earm bip sē pe sceal àna lifgan 'Wretched is he who shall live alone' (HA1: $-\times \times \times \times-\times-\times$ ) (Maxims I 172) and Oft hy wordum tōweorpað (hA1: $\times \times-\times \times-\times$ ) 'Often they throw out words' (Maxims I 189), do not provide definitive evidence because neither verse has a pair to create a complete line, making them unusual to begin with. ${ }^{28}$ Maxims I 189 also has an ambiguous metrical pattern. The cadence is clearly a type A with double alliteration, but the onset only has two syllables, so it could feasibly be analysed as anacrusis. Yet because the syllables are formed by two separate words, both of which are particles, the hypermetric reading is more probable. Maxims I 172 is more convincingly hypermetric. Not only does it have a heavy onset, making for three stress words, it is also a realization of the formulaic system used to articulate wisdom that Momma named "the gnomic formula."

Most of the possible hypermetric verses in Solomon and Saturn have light onsets, but they are not as ambiguous as Maxims I 189 because they all have three or more syllables in the onset. Some have slight irregularities: and hiera winrōd lixxan (hA1: $\times \times \times-{ }^{\prime} \times-\times$ ) 'and their blessed cross shines' (Solomon and Saturn 236b) does not have any particles in the onset; healdað hine niehta gehwylce (hA1: $\left.\times \times \times \times{ }^{\prime} \times \times-\times\right)$ ) '[Two hundred guards] guard it each of nights' (Solomon and Saturn 261a) is in an on-verse but does not have double

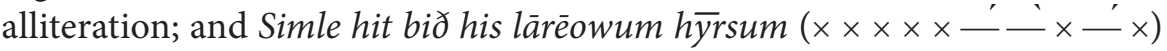
'It is always obedient to its teachers' (Solomon and Saturn 400b) has an extra instance of tertiary stress in the cadence, making for a pattern which does not fit into any of Sievers's five types. However, apart from the last example, these irregularities do occur elsewhere in Solomon and Saturn, so they are not atypical of the poem's composition. Furthermore, there is one line, gegangan géara gehwelce (aHA1: $\left.\times-\times{ }^{\prime} \times \times{ }^{\prime}-\times\right)$ 'each of years [shall] go' (Solomon and Saturn 289a), that opens with a heavy onset and is perfectly regular, so it

28 These verses are typically called orphan verses. Though rare in Old English poetry, a number of them can be found in gnomic poetry. Some have argued that these verses may be related to the Old Norse full line (vollzeilen) in ljóðaháttr, especially because both occur frequently in gnomic poetry (see Bliss 1971). However, the orphan verses do not appear to be a regular feature of the meter, while the full line has a designated place in each stanza. 
is more definitively hypermetric. Hence, while the distribution pattern seems unusual, the relative frequency in this poem in particular suggests that it might not merely be a scribal error. Although the Solomon and Saturn poet does not use as high an incidence of hypermetric verses as the other two gnomic poets, the frequent use of lone hypermetric verses shows that he still adds extra weight to his composition at times.

In total, 21 verses in these poems are distributed in a manner that is not found consistently in the conservative poems. While several of these verses display irregularities that could have been caused by scribal error, some of the irregularities, such as a verse that has no pair or a hypermetric verse with four stresses, occur elsewhere in the gnomic poems and may be features of gnomic metre. The number of atypical verses is small enough that they could all have resulted from scribal error, with an increased number of errors because the metre was unfamiliar enough to the scribes that they were more likely to make mistakes when copying these poems. However, the increased number of unusually distributed verses overall, together with the proportionate decrease in clearly corrupt verses among those unusual verses, means that we should not discount the possibility that these distribution patterns show another way in which the metre of gnomic poems developed differently from that of narrative poems. The difference might be simply a result of the different content. Because gnomic poems focus on a single statement, rather than a narrative sequence, a single hypermetric verse seems appropriate in a gnomic poem, where a single, longer statement could easily stand by itself in the middle of a passage of normal verse.

Yet even though the alternate distribution patterns could have developed naturally given the content of the poems, they still serve to reinforce the overall metrical tendencies of gnomic poetry, allowing the poets to maintain heavier diction. The occasional hypermetric verse in normal passages adds weight or gravity to the section by increasing the length of the line, thereby slowing the pace of the poem at that moment. Even the occasional use of normal verse in hypermetric passages, though not a heavy feature in and of itself, perhaps facilitated the poets' ability to sustain numerous long hypermetric passages. These additional options therefore add to the cumulative effect of all the features under discussion: they allow the poets to consistently compose longer lines, and, in so doing, evoke a sound that the listeners would recognize, causing them to put the poem in the greater context of popular gnomic wisdom. 


\section{Conclusion}

This survey of hypermetric composition in gnomic poetry reveals that gnomic poems are neither irregular nor an entirely separate metre but instead a stylistic variant of traditional hypermetric verses that conforms to and marks gnomic diction. In this variant, verses tend to be longer, more complex, and heavier, and the prominent use of hypermetrics adds to the weight of the poems overall. This style fits with the other features of gnomic poetry; the long lines allow poets to fit their aphorisms into single verses while also giving those statements more importance. Not only do the long lines themselves lend weight to the poems, but the ability to put each gnome in its own verse, to make it both pithy and memorable, also makes it stand out. Significantly, even though the variant style seems primarily designed for individual gnomic statements that appear in lists, it is still used in the longer explanations that span multiple verses in Maxims I and Solomon and Saturn. The consistent use of this style throughout each of the poems demonstrates that it is not merely a practical devise used to fit lists of aphorisms into poetry but rather a stylistic shift that characterizes gnomic verse overall.

This is not to say that all three poems adhere to a completely uniform style; instead, they adhere to the same general principles, but the individual poets apply those principles differently, showing their preferences and creating emphasis in different ways. The Maxims poems in particular create a striking contrast. Where the lines in Maxims I can be long and rambling, the lines in Maxims II use a relatively standard length. Where Maxims I presents a variety of verse types in the cadence, Maxims II has one type hE verse and all the rest use a type $\mathrm{A} 1$ in the cadence. Where Maxims I has numerous examples of lone hypermetric lines, single hypermetric verses in the middle of normal passages, and hypermetric passages that contain normal verses, Maxims II uses hypermetric verses almost entirely in consistent passages. Yet as much as Maxims II appears quite regular in comparison to Maxims $I$, it also uses the unusual pattern of a heavy onset in the off-verse, almost to the exclusion of the more standard light onset. The additional heavy onsets, together with the relatively high proportion of hypermetric verses overall, make for much heavier lines. When recited, the different verses in the two poems must have taken on similar gravity, either through the length added by the long drop, the weight added by the extra lift, or both.

Solomon and Saturn bears less similarity to the two Maxims poems, yet it is still comparable in many ways. While it does not have as high a proportion of hypermetric verse, it does have a relatively large number of them (50 verses) when compared to other Old English poems. It also distributes these verses 
in unusual ways, inserting them into normal passages, thereby drawing out the lines as the poet saw fit. In addition, the length of some of the hypermetric lines could be quite extreme. Heavy, expansive lines therefore seem to be a characteristic quality of Solomon and Saturn as well, one that the hypermetric passages serve to reinforce. Thus, even though each poem has its own individual style, all share some more unusual features, and in each case the features combine to form a compositional style that is distinctly heavy.

This gnomic style may have developed as a result of the desire to draw the audience more fully into the material, making a sound to match the content that marks the nature of the poem. In his explanation of the significance of formulaic language, John Miles Foley (1995) argues that poets use traditional diction not just because doing so makes poems easy to compose and memorize or even because they want their poetry to fit seamlessly into the tradition, but rather because the poets can refer metonymically to a broad range of associations that the language evokes. He asserts that "the traditional phrase or scene or story-pattern has an indexical meaning vis-à-vis the immanent tradition; each integer reaches beyond the confines of the individual performance or oralderived text to a set of traditional ideas much larger and richer than any single performance or text" (6). The traditional features that Foley discusses are the turns of phrase or formulaic systems that poets use to evoke a number of associations that could further characterize the person or event being referenced, but poetic style might be an additional feature that could elicit a particular response in an oral system where sound is key. If the audience is accustomed to associating a particular poetic style with a certain set of subject material, hearing that style could evoke the connotations and associations that go with it.

In a way, the metrical distinctions could work similarly to the lexical distinctions of register. In the course of his discussion of poetic language, Foley defines register in this context as "an idiomatic version of the language that qualifies as a more or less self-contained system of signification specifically because it is the designated and sole vehicle for communication in the act of traditional oral performance" (15). Foley focuses on lexical features such as a traditional poetic koiné, showing how lexical features distinguish poetry as a register separate from prose and, in the process, allow those familiar with the tradition to understand the associations and meanings implicit to it. Expanding of Foley's work, Frog (2012: 54) argues that, especially in the variety of metres found in Old Norse poems, the register is related to the metre and mode of expression, arguing that different modes of expression can have an effect on the metre, since the word choice would influence the rhythms of the poem. These both in turn can have an effect on the register and so, Frog 
argues, they should "be considered a determinant on register rather than part of the register itself” (54).

Frog's distinctions can explain part of what this study has argued about hypermetric diction in gnomic poetry. As I have shown above, the diction and turns of phrase associated with gnomic statements are a large part of what shapes the gnomic hypermetric patterning, just as Frog argues the modes of expression would. ${ }^{29}$ What is significant about gnomic poetry, then, is that the distinctive metrical patterning remains even when the characteristic diction is not being used, so the shift in mode of expression at these points does not necessarily impact the metre. In these poems, then, the metre serves consistently to reinforce the register, even when the diction of the poem does not, creating a distinctive sound for these particular gnomic poems. Even though it is not possible to categorize Old English poems into entirely distinctive genres, the sustained difference in style of the gnomic poems suggests such categorization was not entirely foreign and that there were some associations between some groups of poems. By using a style specifically aligned with gnomic poetry, gnomic poets may have been evoking the "more or less self-contained system of signification" that Foley describes in order to elicit a particular response from the audience.

Wisdom poetry in particular would warrant its own stylistic distinctions because it is very important to the Old English tradition. Gnomic statements appear often in a large range of poems, as well as several poems that are dedicated purely to sharing maxims; as the Maxims I poet says Gleawe men sceolon gieddum wrixlan 'wise men should exchange maxims' (Maxims I 4a). The audience would therefore be used to hearing gnomes - often in lists that add to an overall understanding of nature, society, and God - and probably had a store of their own. A separate, traditional gnomic style would allow listeners to associate the wisdom they hear with other wisdom they have heard in order to construct a larger list in their minds that more fully explains the nature of the world. The extensive use of hypermetrics with this long and heavy style could therefore serve to both alert the audience to the associations they should make

29 Rebecca Fisher makes a similar argument about metrical charms: "The most important characteristic of the Parry-Lord formula is that a formula consists of a set of words that conforms to the rules of metre and represents a simple, single idea. However, a charm unit is not restricted by metre but by register, meaning that it must conform to the purpose and tone of the charm as a whole, maintaining the appropriate semantic field" (2011: 39). This argument suggests that the poets were primarily concerned with maintaining the language considered appropriate to charms, creating a metre appropriate to that end when casting charms in a poem. This may be the reason why scholars such as Roper (2000) have been able to isolate distinguishing stylistic features in the metrical charms, just as I have done here for gnomic poetry. 
and characterize the information that is being shared. Features such as extraheavy lines with two heavy onsets, hypermetric verses that intrude in normal passages, and four-stress verses that stand out from even normal hypermetric verses add to the solemn and weighty tone that marks such wisdom even as they alert the audience to the nature of the poem. Thus, by using the flexibility inherent in hypermetric verse to create a large number of hypermetric patterns that add more solemnity to the line, gnomic poets distinguish their style of composition from narrative verse and mark their poems in a way that the audience could have heard and recognized as an indication of important knowledge that fits into the larger context of Old English wisdom that is meant to be shared.

\section{References}

Bliss, Alan 1967. The Meter of Beowulf, revised edn. Oxford: Blackwell.

Bliss, Alan 1971. Single half lines in Old English poetry. In: Notes and Queries 18, 442-449.

Bredehoft, Thomas A. 2003. The three varieties of Old English hypermetric versification. In: Notes and Queries 50.2, 153-56.

Bredehoft, Thomas A. 2004. Ælfric and late Old English verse. In: Anglo Saxon England 33, 77-107.

Bredehoft, Thomas A. 2005. Early English Metre. Toronto: University of Toronto Press.

Cable, Thomas 1991. The English Alliterative Tradition. Philadelphia: University of Pennsylvania Press.

Campbell, Alistair 1983. Old English Grammar. Oxford: Oxford University Press.

Fisher, Rebecca 2011. Writing charms: The transmission and performance of charms in Anglo-Saxon England. Sheffield: University of Sheffield dissertation.

Foley, John Miles 1995. The Singer of Tales in Performance. Bloomington: Indiana University Press.

Frog 2012. On the case of Vambarljó $ð$ II: Register and mode from skaldic verse to sagnakvoði. In: RMN Newsletter 5, 49-61.

Fry, Donald K. 1967. Old English formulas and systems. In: English Studies 48, 193-204.

Fulk, Robert Dennis 1992. A History of Old English Metre. Philadelphia: University of Pennsylvania Press. 
Fulk, Robert Dennis; Bjork, Robert E.; Niles John D. (eds.) 2008. Klaeber's Beowulf and the Fight at Finnsburg. Toronto: University of Toronto Press.

Hartman, Megan E. 2010. The syntax of Old English hypermetrics. In: English Studies 91, 477-91.

Hartman, Megan E. 2014. Poetic attitudes and adaptations in late Old English Verse. In: Leeds Studies in English.

Hutcheson, Rand 1995. Old English Poetic Metre. Cambridge: D. S. Brewer.

Krapp, George P.; Dobbie, Elliott Van Kirk (eds.) 1931-53. The Anglo-Saxon Poetic Records, 6 vols. New York: Columbia University Press.

Kuhn, Hans 1969. Zur Wortstellung und -betonung im Altgermanischen. In: Beiträge zur Geschichte der Deutschen Sprache und Literatur 57 (1933). Repr. In Kleine Schrigten 1. Berlin: Gruyter. 18-103.

Momma, Haruko 1989. The 'gnomic formula' and some additions to Bliss's Old English metrical system. In: Notes and Queries 4, 423-426.

Momma, Haruko 1997. The Composition of Old English Poetry. Cambridge: Cambridge University Press.

Pope, John C. 1966. The Rhythm of Beowulf. New Haven: Yale University Press.

Pope, John C.; Fulk, Robert Dennis 2001. Eight Old English Poems, $3^{\text {rd }}$ ed. New York: W. W. Norton and Company.

Roper, Jonathan 2000. Metre in the Old English 'Metrical' Charms. In: Mikhailova, T., J. Roper, A. Toporkov, and D. Nikolayev (eds), Oral Charms in Structural and Comparative Light. Moscow: PROBEL-2000, 116-121.

Russom, Geoffrey 1987. Old English Metre and Linguistic Theory. Cambridge: Cambridge University Press.

Shippey, Thomas A. 1976. Poems of Wisdom and Learning in Old English. Cambridge: D. S. Brewer.

Shippey, Thomas A. 1994. The Wanderer and The Seafarer as wisdom poetry. In: Aertsen, Henk; Rulf H Bremmer, Jr. (eds.), Companion to Old English Poetry. Amsterdam: VU University Press, 145-158.

Sievers, Eduard 1887. Der angelsachsische schwellvers. In: Beitrage zur Geschichte der Deutschen Sprache und Literatur 12, 454-82.

Sievers, Eduard 1893. Altgermanische Metric. Halle: Max Niemeyer. 
Simms, Douglas 2003. Reconstructing an oral tradition: Problems in the comparative metrical analysis of Old English, Old Saxon, and Old Norse alliterative verse. Austin: University of Texas at Austin dissertation.

Stanley, Eric Gerald 1984. Alliterative ornament and alliterative rhythmical discourse in Old High German and Old Frisian compared with similar manifestations in Old English. In: Beiträge zur Geschichte der Deutschen Sprache und Literatur 106, 184-217.

Suzuki, Seiichi 1996. The Metrical Organization of Beowulf. New York: Mouton de Gruyter.

Suzuki, Seiichi 2004. The Metre of Old Saxon poetry: The Remaking of Alliterative Tradition. Cambridge: D.S. Brewer. 